\title{
МИГРАЦИЯ ТОКСИЧНЫХ ЭЛЕМЕНТОВ В ПРЕДЕЛАХ ЕРМАКОВСКОГО ФЛЮОРИТ-БЕРТРАНДИТ- ФЕНАКИТОВОГО МЕСТОРОЖДЕНИЯ
}

\author{
А. М. Плюснин, Д. М. Сандакова \\ Геологический институт СО РАН, Россия \\ ПАО «Бурятзолото», Россия \\ Поступила в редакиию 11 апреля 2019 г.
}

\begin{abstract}
Аннотация: В статье рассмотрены условия хранения отходов добычи Ермаковского бериллиевого месторождения. Приводятся данные по содержанию бериллия, фтора, цинка, кадмия, мышьяка и др. токсичных элементов в рудничных и поверхностных водах, почвах и растительности в пределах месторождения и на окружающей территории. Показано, что миграция токсичных элементов, в основном, происходит в твердой фазе в составе продуктов выветривания отходов добычи руд. Поверхностные и подземные воды, формирующие ресурсы и химический состав в пределах рассматриваемой территории имеют слабощелочную реакцию среды, загрязняются сульфат-ионом, железом, марганцем. Растительность загрязнена цинком и кадмием.
\end{abstract}

Ключевые слова: бериллий, фтор, карьер, отвалы, наледь, выветривание, миграция.

\section{Migration of toxic elements within the Ermakovskoye fluorite-bertrandite-phenakite deposit}

\section{A. M. Plyusnin, D. M. Sandakova}

Abstract: The article discusses the conditions of mining wastestorage withinthe Ermakovskoyeberyllium deposit. Data on the content of beryllium, fluorine, zinc, cadmium, arsenic and other toxic elements in mine and surface waters, soils and vegetation within the depositand in the surrounding area are presented. It is shown that the migration of toxic elements mainly occurs in the solid phase in the composition of weathering products of ore mining waste. Surface and underground waters, forming resources and chemical composition within the area, have a slightly alkaline reaction of the medium, are polluted with sulfate ion, iron, manganese. The vegetation is contaminated with zinc and cadmium.

Key words: beryllium, fluorine, quarry, waste dumps, frost, weathering, migration.

\section{ВВЕДЕНИЕ}

Бериллий и его соединения по токсичному воздействию на биоту относятся к первому классу опасности. Особенно опасны его летучие соединения, а также образующаяся при обработке пыль, вызывающая кожные заболевания и заболевания органов дыхания [9]. Этот токсичный элемент в больших количествах извлекается из недр при разработке рудных месторождений. В представленной публикации рассмотрено поведение бериллия

() Плюснин А.М., Сандакова Д.М., 2019

Материал статьи доступен по лицензии Creative Commons "Attribution" 4.0 и других токсичных элементов в постэксплуатационный период на территории размещения отходов добычи флюорит-бертрандит-фенакитового месторождения.

Ермаковское месторождение отрабатывалось с 1975 по 1989 году открытым способом. Действовали карьер, отвалы вскрышных пород, корпус дробления, котельная, вспомогательные цеха. Дробленая руда с Кижингинского карьера для дальнейшей переработки увозилась железнодорожным транспортом на фабрику в пос. Первомайский Забайкальского края. За время эксплуатации было отработано около половины запасов с извлечением 9733 тыс. м³ горных пород, в том числе: вскры- 


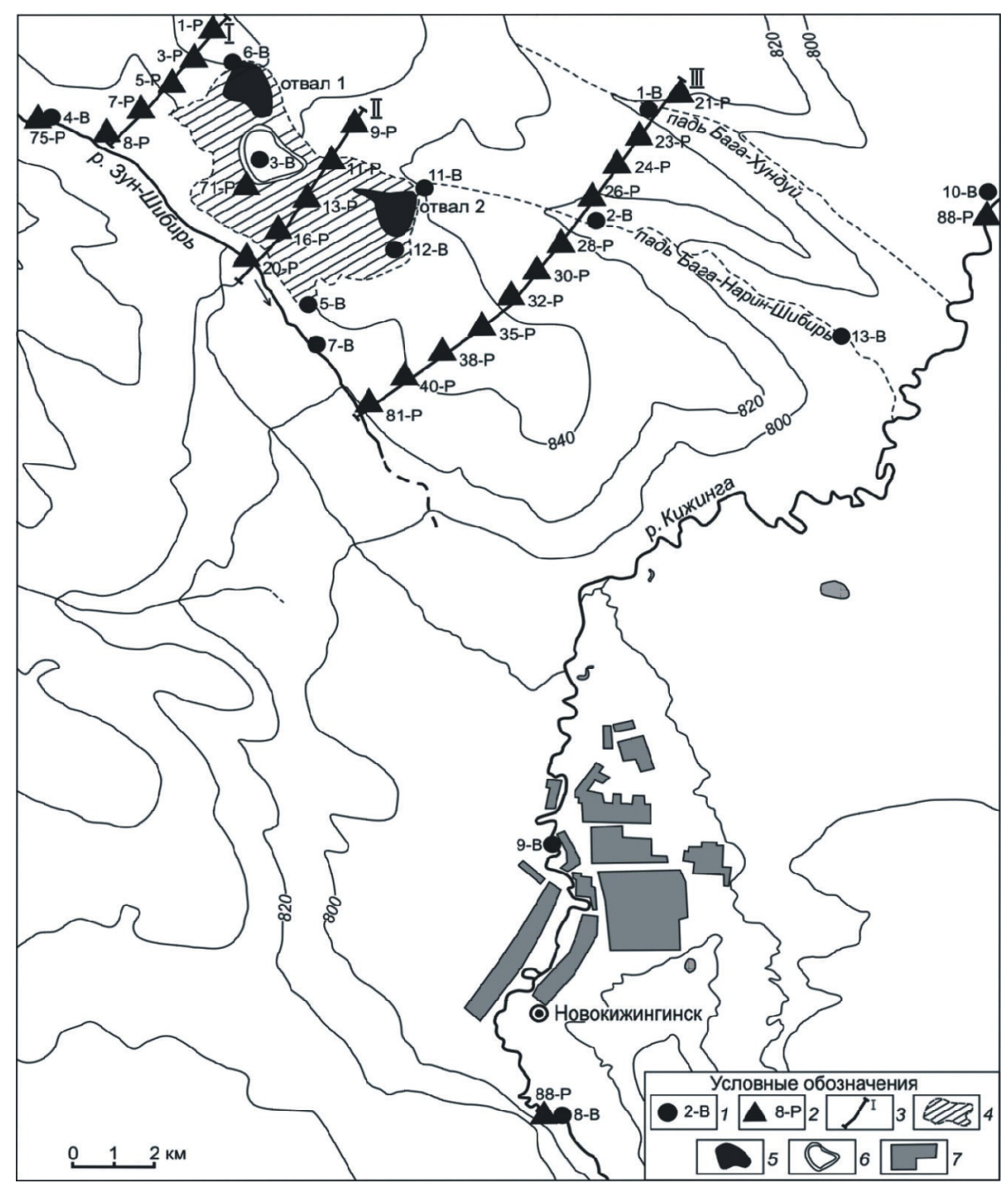

Puс. Схема расположения природно-техногенных образований на территории Ермаковского месторождения с местами отбора проб воды и наледей

Условные обозначения: 1 - места отбора проб воды, 2 - места отбора проб растительности, 3 - расположение профилей отбора проб почвы, 4 - территория занятая природно-техногенной системой рудника, 5 - отвалы вскрышных пород, 6 - карьер, 7 - населенный пункт

ши - 9450 тыс. м³. После закрытия рудника, работы по рекультивации и восстановлению природных компонентов ландшафта не проводились. Учитывая высокую потенциальную опасность бериллия на биоту, информация о поведении основных токсичных элементов, находящихся в составе отходов разработки бериллиевых руд, при длительном хранении, имеет большое практическое значение для организации природоохранных мероприятий.

\section{МЕТОДИКА ИССЛЕДОВАНИЯ}

В 2007 и 2013 годах на территории Ермаковского месторождения проводились геоэкологические исследования, которые включали маршрутное обследование территории, опробование вод, почв, растительности. Было отобрано 24 пробы воды,
86 проб почв, 12 проб донных отложений и 25 проб травяного покрова (рис.).

Почвенная съемка была проведена в соответствии с ГОСТ 17.4.3.01-83, ГОСТ 17,4,4,4,02-84 и ГОСТ 28168-89. Пробы почвы отбирались из поверхностного слоя земли с погружением на глубину 0,0-0,1 м методом «конверта» (смешанная проба с площади 20-25 м²). В полевых условиях пробы травы высушивались, озолялись, затем растирались до пылевого состояния и упаковывались в пластиковые пакетики. Пробы воды отбирались согласно ГОСТ 17.1.5.05-85, рекомендациям Р. 52.24.353-94 с поверхности водного объекта. Сразу после отбора пробы определялись: растворенный кислород, диоксид углерода, $\mathrm{pH}$, температура воды, запах, прозрачность. Затем отобранная 
проба воды разливалась по разным, специально подготовленным по видам определяемых показателей сосудам и консервировалась в соответствии с требованиями методик. Общий химический анализ производился в аттестованной лаборатории Бурятского ЦГМС. Определение микрокомпонентного состава проводилось в центре коллективного пользования Геологического института СО РАН. Для анализа использовались методы атомно-абсорбционной спектрометрии и индуктивно связанной плазмы (ICPMS).

\section{ФИЗИКО-ГЕОГРАФИЧЕСКАЯ ХАРАКТЕРИСТИКА РАЙОНА}

Район занимает обширное Кудуно-Кижингинское межгорное понижение. Территория с севера ограничена хребтом Худанский, с юга-востока хребтом Цаган-Хуртэй, а с запада - горной цепью Цаган-Дабан [2, 3].

Рельеф имеет сопочно-увалочный характер, характеризуется малым колебанием абсолютных высот и слабым развитием эрозионных процессов. Гидрографическая сеть района принадлежит к бассейну р. Селенги. Наибольший расход воды в реках наблюдается в период летних дождей [2]. На возвышенных участках месторождения отмечены дерново-лесные неоподзоленные почвы, в которых верхний гумусовый горизонт подвергнут изменениям или полному уничтожению. В понижениях рельефа на слабонаклонных подгорных шлейфах южной и юго-восточной экспозиции распространены темно-каштановые мучнисто-карбонатные почвы. На дне и в окрестностях карьеров, на терриконах и промплощадках, почвенный покров отсутствует.

В составе растительного покрова доминирующим является лесной тип растительности, которая представлена бореальными таежными светлохвойными лесами, где господствует сосна обыкновенная. В котловинах на возвышенных участках отмечаются остепненно-травяные сосняки. Днище котловин представлено разнотравно-злаковыми сообществами. Котловинные участки на значительной территории распаханы. Климат типичный для Забайкалья - резко континентальный с продолжительной малоснежной и суровой зимой и коротким жарким летом с дефицитом влажности [4].

\section{ГЕОЛОГИЧЕСКОЕ СТРОЕНИЕ И ХАРАКТЕРИСТИКА ПРИРОДНО- ТЕХНОГЕННОЙ СИСТЕМЫ}

Ермаковское месторождение приурочено к небольшому блоку осадочных пород, представлен- ных доломитами, кристаллическими сланцами и мраморизованными известняками. Толща осадочных пород рассекается многочисленными дайками [7]. Оруденение на месторождении представлено несколькими минеральными и генетическими типами, преобладают фенакит-бертрандитовые руды. Оно в основном приурочено к контакту алюмосиликатных сланцев с известняками и образует серию межпластовых тел, объединенных в рудные зоны. Руды в основном представлены мелко- и среднезернистыми агрегатами массивной, участками массивно-пятнистой текстуры. Зона окисления развита слабо, распространяясь на глубину первых десятков метров вдоль тектонических нарушений $[5,6,7]$. Месторождение приурочено к водоразделу ручья Зун-Шибирь и падей Бага-Хундуй и Бага-Нарин-Шибирь (рис.).

Карьер имеет вытянутую форму в северо-восточном направлении с длиной по верху 650 м, шириной 500 м и глубиной 70 м. Стенки карьера обрушены. В верхних горизонтах зона выветривания представлена суглинками с дресвой и щебнем. В приповерхностных горизонтах и вдоль тектонических нарушений руды покрыты буроватыми налетами гидроксидов железа, в них появляются каверны и пустоты, в которых иногда наблюдаются игольчатые сростки каламина, англезита и белые порошковатые налеты монтмориллонита и каолинита, изредка - тонкие пленки и почковидные агрегаты малахита. Отвалы вскрышных пород состоят из мраморов, гранитов, сланцев, габбро-диоритов, известняков, сланцев и скарнов. Основными источниками подвижных форм элементов выступают участки, где происходит выветривание сульфидов - пирита, галенита и сфалерита. На этих участках происходит окисление сульфидной минерализации с образованием минеральных кислот, взаимодействующих с флюоритом, фенакитом, бертрандитом, микроклином, альбитом, слюдами, переводя ряд токсичных элементов в раствор. Твердые продукты выветривания разносятся ветром по окрестностям.

\section{ПОЛУЧЕННЫЕ РЕЗУЛЬТАТЫ}

В карьере за счет выпадения атмосферных осадков образовался бессточный водоем. Нами опробована вода, заключенная в этом водоеме.

Отвалы вскрышных пород хорошо проницаемы для газов и воды. При выпадении атмосферных осадков в пределах отвалов вскрышных пород вся вода переводится в подземный сток. Летом в крупно глыбовом материале отвалов формируются конденсационные воды. В осенне-зимний 
Содержание элементов в почвогрунтах и почве на Ермаковском бериллиевом месторождении и окружающей территории, мг/кг

\begin{tabular}{|c|c|c|c|c|c|c|c|c|c|}
\hline Химический элемент & $\mathrm{Be}$ & As & $\mathrm{Hg}$ & $\mathrm{Cu}$ & $\mathrm{Ni}$ & $\mathrm{Pb}$ & $\mathrm{Cd}$ & $\mathrm{Co}$ & $\mathrm{Zn}$ \\
\hline \multicolumn{10}{|c|}{ Отвал №1 } \\
\hline Минимальное & 33,2 & 1,6 & 0,029 & 11,2 & 10,2 & 17,2 & 1,5 & 5,9 & 56 \\
\hline Максимальное & 41,2 & 2,2 & 0,14 & 20,3 & 11,8 & 55 & 2,3 & 7,6 & 86 \\
\hline Среднее & 36 & 1,96 & 0,061 & 15 & 10,9 & 39,2 & 1,8 & 6,7 & 65 \\
\hline \multicolumn{10}{|c|}{ Отвал №2 } \\
\hline Минимальное & 26,7 & 1,6 & 0,025 & 5,6 & 6,9 & 8,4 & 0,75 & 4,4 & 18 \\
\hline Максимальное & 241 & 3,3 & 0,064 & 47 & 36 & 453 & 8,1 & 30,1 & 1088 \\
\hline Среднее & 91 & 2,22 & 0,04 & 18,9 & 18 & 69,6 & 2 & 13,5 & 174 \\
\hline \multicolumn{10}{|c|}{ Профиль I } \\
\hline Минимальное & 0,62 & 0,1 & 0,031 & 7,9 & 10,1 & 4,8 & 0,25 & 6,3 & 4,2 \\
\hline Максимальное & 2,6 & 0,75 & 0,12 & 13,1 & 14,3 & 52 & 2,1 & 9,8 & 155 \\
\hline Среднее & 1,58 & 0,42 & 0,07 & 11,3 & 12,5 & 21,1 & 1,21 & 7,99 & 68,0 \\
\hline \multicolumn{10}{|c|}{ Профиль II } \\
\hline Минимальное & 4,1 & 0,87 & 0,03 & 5,8 & 6,3 & 8,8 & 0,16 & 5,3 & 29 \\
\hline Максимальное & 20,7 & 1,4 & 0,04 & 31 & 22,8 & 113 & 2,3 & 15,5 & 200 \\
\hline Среднее & 12,9 & 1,09 & 0,0345 & 16,4 & 16,2 & 51,8 & 0,99 & 11,8 & 97 \\
\hline \multicolumn{10}{|c|}{ Профиль III } \\
\hline Минимальное & 1,2 & 0,1 & 0,022 & 6,5 & 4,1 & 5,5 & 0,46 & 5,9 & 22 \\
\hline Максимальное & 3,7 & 0,45 & 0,055 & 11,9 & 13,3 & 15,5 & 1,3 & 7,5 & 48 \\
\hline Среднее & 2,28 & 0,28 & 0,04 & 8,6 & 8,7 & 11,8 & 0,8 & 6,7 & 35 \\
\hline ФоH & 4,37 & 1,4 & 0,1 & 6,73 & 5,6 & 6,9 & 0,38 & 5,2 & 23,3 \\
\hline ПДК мг/кг & 3 & 2 & 2,1 & 33 & 20 & 32 & 0,5 & 10 & 55 \\
\hline
\end{tabular}

период в местах близ поверхностного залегания грунтовых вод формируются наледи. Две наледи формируются у отвала № 2 с восточной и южной стороны, соответственно наледь один и два. Третья наледь образуется за счет разгрузки воды из штольни. Четвертая - в долине ручья Зун-Шибирь ниже по склону от колодца, принимающего поверхностный сток с промплощадки.

Формирование макрокомпонентного состава вод под воздействием техногенных образований приводит к увеличению содержания сульфат-иона и возрастанию содержания фторид-иона, отмечается повышенное содержание нитрат-иона.

Необходимо отметить, что рудничные воды характеризуются околонейтральным состоянием кислотно-основных условий среды. Это, на наш взгляд, определяет невысокую миграционную способность многих химических элементов. Наиболее активно в этих условиях переходят в раствор микроэлементы, образующие в растворе анионы - марганец и молибден. Из тяжелых металлов отмечаются в повышенных концентрациях цинк и свинец. Среди элементов, относящихся к первой и второй группе токсичности, в повышенных концентрациях обнаруживаются кадмий и ртуть, со- держание которых превышает ПДК, установленные для водоемов рыбохозяйственного назначения. Содержание бериллия в рудничных водах невысокое.

Непосредственно в районе месторождения формируются временные водотоки пади Бага-Нарин-Шибирь и пади Бага-Хундуй. Юго-западная часть рассматриваемой природно-техногенной системы дренируется подземными и поверхностными водами пади Зун-Шибирь. В верховье пади Зун-Шибирь протекает постоянный ручей, который переходит в подземный сток в ее средней части. Подземный сток всех этих падей дренируется рекой Кижинга. Гидрохимическая съемка проводилась в конце весны - начале лета, когда во всех падях сохранялся поверхностный сток. Вода в ручьях пресная, прозрачная, без вкуса и запаха, величина сухого остатка составляет 51-1165 мг/л.

Выявленные гидрохимические параметры показывают, что воздействие Ермаковского бериллиевого месторождения проявляется в возрастании содержания сульфат-иона и изменении $\mathrm{pH}$ в сторону кислой реакции среды в ручье Зун-Щибирь.

В поверхностных водотоках обнаруживаются повышенные концентрации железа, марганца, молибдена и цинка, что может быть связано с воз- 
Суммарный показатель загрязнения на обследованной территории

\begin{tabular}{|l|c|c|}
\hline \multicolumn{1}{|c|}{ Участок } & $\begin{array}{c}\text { Величина суммарного } \\
\text { показателя загрязнения } \\
\text { почв }(\mathrm{Zc})\end{array}$ & $\begin{array}{c}\text { Категория загрязнения площадок } \\
\text { отбора проб на участке }\end{array}$ \\
\hline Карьер & от 56,3 до 1082,8 & $\begin{array}{c}\text { от опасной до чрезвычайно- } \\
\text { опасной }\end{array}$ \\
\hline $\begin{array}{l}\text { Верхняя площадка и подножье } \\
\text { отвала №1 }\end{array}$ & от 12,4 до 26,5 & $\begin{array}{c}\text { от «допустимой» до «умеренно- } \\
\text { опасной» }\end{array}$ \\
\hline $\begin{array}{l}\text { Верхняя площадка и подножье } \\
\text { отвала №2 }\end{array}$ & от 3,9 до 78,6 & $\begin{array}{c}\text { от «допустимой» до «опасной» } \\
\text { Профиль I }\end{array}$ \\
\hline Профиль II & от 3,1 до 18,4 & $\begin{array}{c}\text { от «допустимой» до «умеренно- } \\
\text { опасной» }\end{array}$ \\
\hline Профиль III & от 0,2 до 29,8 & $\begin{array}{c}\text { от «допустимой» до «умеренно- } \\
\text { опасной» }\end{array}$ \\
\hline
\end{tabular}

действием техногенных процессов, протекающих в природно-техногенной системе. Содержание бериллия в поверхностных водах невысокое, так как он плохо мигрирует в слабо щелочной и нейтральной среде.

Содержания основных загрязнителей в почвах представлены в таблице 1, они приведены в сравнении с концентрацией этих химических элементов в почвогрунтах отвалов вскрышных пород.

Отвалы вскрышных пород выступают в качестве основного поставщика загрязняющих веществ в соседний не затронутый горными работами ландшафт. Все рассматриваемые токсичные металлы и мышьяк здесь присутствуют в максимальных концентрациях. Максимальное содержание бериллия достигает 241 мг/кг. Значительные содержания Ве находятся в пробах почв, отобранных на профиле II - до 20,7 мг/кг. Содержание Ве в почве на фоновых участках составляет 1,5-9,9 мг/кг. Относительно повышенное содержание бериллия на фоновом участке, по нашему мнению, объясняется воздействием рудообразующих процессов на смежную территорию, значительно превышающую площадь месторождения.

Отвалы служат источником загрязнения окружающей территории цинком, свинцом, кадмием и мышьяком. Их содержание превышает предельно допустимые концентрации, установленные для почв. На профиле II, проходящем через промплощадку, в почвах установлены повышенное содержание этих же элементов. На других профилях содержание всех рассматриваемых загрязнителей значительно ниже предельно допустимых концентраций. Содержание $\mathrm{Hg}$ на всех участках незначительное и колеблется в пределах от 0,022 мг/кг до 0,14.
Степень химического загрязнения почв была оценена по суммарному показателю загрязнения по формуле:

$$
Z c=\sum_{i=1}^{n} K c i-(n-1),
$$

где $n$ - число токсикантов;

$K i$ - коэффициент концентрации $i$-го компонента. Он определяется по формуле (2):

$$
K c i=\frac{C i}{C i \phi},
$$

где $C$ - содержание $i$-го элемента в объекте воздействия; $C i \phi b$ - фоновое содержание $i$-го элемента.

Присутствие элементов в почвах выше местного фона $(K c>1)$ указывает на накопление и активное участие в процессе почвообразования, а ниже $(K c<1)$ - на вынос элементов при почвообразовании.

Суммарный показатель загрязнения на обследованной территории изменяется от $Z c<16$ до $Z c=1082,8$, т.е. категория загрязнения рассматриваемой территории изменяется от «допустимой» до «чрезвычайно опасной» [5]. В таблице 2 приведен суммарный показатель загрязнения рассмотренных нами участков.

К загрязненной территории с разной степенью опасности относятся территория карьера, отвалов и промышленной площадки. Рассеивание загрязнения на окружающую территорию, вероятно связано с ветровой и водной эрозией на техногенных образованиях.

В травяном покрове выявлены превышения ПДК по цинку и кадмию. Концентрация $\mathrm{Cu}, \mathrm{Ni}$, $\mathrm{Pb}$ и $\mathrm{Cr}$ в травяном покрове незначительна. 
Наиболее высокая концентрация цинка установлена на левом берегу ручья Зун-Шибирьв районе промплощадки. Его концентрация здесь достигает 360 мг/кг. На профиле II, заложенном на промплощадке, содержание цинка составляет от 107 мг/кг до 237 мг/кг, что выше предельно допустимой концентрации. Здесь же выявлено загрязнение растительности кадмием. В отдельных пробах растений установлены повышенные содержания хрома и свинца. Загрязнение растительности указывает на то, что эти элементы присутствуют в почвах в подвижных формах.

\section{ОБСУЖДЕНИЕ РЕЗУЛЬТАТОВ}

Основным источником загрязнения почвы, paстительности, поверхностных и подземных вод являются отвалы вскрышных пород, в которых присутствует некоторая доля бериллиевой минерализации, флюорита и сульфидных минералов. Отвалы располагаются на водораздельном пространстве и подвергаются воздействию ветра и атмосферных вод.

Выветривание отходов добычи бериллиевых руд на этом месторождении в настоящее время сопровождается формированием слабо щелочных поровых вод. Щелочная среда, установившаяся в поровых водах отвалов, препятствует активной миграции железа и других тяжелых металлов, которые переходят в раствор при окислении сульфидных минералов. Судя по количеству сульфат-иона, процесс окисления сульфидов довольно активно протекает в толще отходов добычи, но, вероятно, в нем участвуют в основном сфалерит, галенит и в значительно меньшей степени пирит и халькопирит. Такое предположение основано на установленных нами ранее закономерностях окисления сульфидной минерализации в хвостах переработки руд [8]. В этой работе показано, что на ранних стадиях хранения отходов в условиях конкуренции за растворенный в воде кислород, окислению подвергаются сульфидные минералы цинка и свинца. При их окислении формируется слабо щелочная среда. В растворенном состоянии обнаруживаются продукты разложения именно этих сульфидов. Образующиеся растворы слабо взаимодействуют с вмещающими породами, поэтому в них мало меди, железа и многих других токсичных элементов, включая бериллий и фтор, которые в достаточно высокой концентрации присутствуют в отвалах горных пород. Но такое состояние кислотно-основных условий среды в отходах добычи при продолжительном хранении будет меняться.
Постепенно, растворенный в инфильтрующихся водах кислород, будет расходоваться на окисление пирита, халькопирита, в результате чего в растворе будет накапливаться серная кислота и установится кислая среда. Кислые растворы начнут активно взаимодействовать с флюоритом, рудой, с вмещающими оруденение породами. В результате этого повыситься минерализация растворов, возрастет концентрация многих микроэлементов, включая бериллий. Ведь известно, что главную роль среди минералов бериллия играют силикаты, несколько меньшее значение имеют окислы и фосфаты. Сульфиды среди минералов бериллия отсутствуют. Основная масса бериллия в магматических породах связана с плагиоклазами, где бериллий замещает кремний. Высокие концентрации бериллия характерны для некоторых темноцветных минералов и мусковита. Его содержание достигает десятков даже сотен мг/кг. Все эти минералы активно разрушаются в результате протекания реакции гидролиза в кислой среде. В нейтральной и слабо щелочной среде скорость их выветривания значительно ниже. Накапливание бериллия в растворе в сильной мере связано с комплексообразованием, в качестве лигандов для образования комплексных соединений выступают анионы минеральных кислот и промежуточные продукты разложения сульфидов $-\mathrm{S}_{2} \mathrm{O}_{3}{ }^{2-}, \mathrm{S}_{4} \mathrm{O}_{6}{ }^{2-}$, $\mathrm{SO}_{4}{ }^{2-}, \mathrm{Cl}^{-}, \mathrm{F}^{-}$. Сейчас содержания этих компонентов в поровых водах отходов добычи небольшие и комплексообразованиене оказывает большого влияние на повышение концентрации бериллия в растворе.

Установленное относительно низкое содержания фторид-иона в поровых водах отходов добычи, несмотря на то, что в них присутствует флюорит, связано с тем, что в составе макрокатионов в этих водах доминирует кальций. С изменением $\mathrm{pH}$ растворов из алюмосиликатных пород в раствор будет поступать натрий и, соответственно, будет расти концентрация фторида.

Установленное периодическое возрастание в поверхностных водах, дренирующих Ермаковское бериллиевое месторождение, концентрации сульфат-ион, железа, марганца и молибдена, связано с непостоянным режимом разгрузки в водотоки грунтовых вод. Вероятно, большую роль в этом играют процессы, связанные с формированиемдеградацией сезонной и многолетней мерзлоты.

Периодическое замерзание и оттаивание деятельного слоя оказывает большое влияние и на миграцию вещества в твердом состоянии. При 
мерзлотном разрушении горных пород формируется легкоподвижная тонкая фракция, которая обладает большой, активной поверхностью. Поведение бериллия в корах выветривания определяется свойствами берилла. Ввиду высокой устойчивости этого минерала в зоне выветривания, бериллий накапливается в верхних частях коры выветривания за счет выноса кремнезема и щелочей и соответственно уменьшения объема породы [1]. При выветривании гранитоидов бериллий сорбируется глинистыми минералами, которые могут легко переноситься ветром и текучей водой. В рассматриваемой природно-техногенной системе загрязнение почв связано с ветровой и водной эрозией отвалов вскрышных пород и техногенно-нарушенной территории. Состав элементов загрязнителей соответствует составу добываемых руд. В связи с распространением на участке выровненных форм рельефа механическое перемещение материала пока не происходит далеко за границы лицензионного участка.

Загрязнение растительности цинком и кадмием, на наш взгляд, связано с тем, что именно эти элементы наиболее активно мигрируют в растворенном состоянии и поэтому усваиваются растительностью. Но такое положение вещей при продолжительном хранении отходов без рекультивации территории нарушится, когда в окислительный процесс включатся халькопирит и пирит, при окислении которых будет генерироваться серная кислота. Тогда установится кислая среда и в миграцию вовлечется более широкий спектр токсичных элементов, которые будут извлекаться не только из сульфидов, но и из вмещающих пород и ореол загрязнения растительности в значительной степени увеличится.

\section{ЗАКЛЮЧЕНИЕ}

Природно-техногенная система Ермаковского бериллиевого месторождения оказывает влияние на все компоненты ландшафта окружающей территории. Под воздействием выветривания пород, заключенных в отвалах вскрыши, формируются лито- и гидрохимические потоки рассеивания фтоpa, цинка, свинца, кадмия и мышьяка. Их содержание превышает предельно допустимые концентрации, установленные для почв и вод. В растительности, произрастающей на территории, затронутой техногенным воздействием, в повышенных концентрациях обнаружены цинк и кадмий. Бериллий в сложившихся условиях на окружающую территорию мигрирует за счет ветровой и водной эрозии с техногенных отложений.
Для устранения негативного влияния отходов разработки Ермаковского месторождения необходимо провести планирование отвалов горных пород. Для устранения образования конденсационной влаги в грубообломочных образованиях вскрышных пород перекрыть отходы добычи тонкозернистым материалом. Для снижения рассеивания токсичных элементов за счет ветровой и водной эрозии закрепить рыхлые отложения растительностью.

Исследование выполнено в рамках государственного задания ГИН СО РАН по проекту IX.137.1.4. «Взаимодействие в системе..» № гос. рег. АAАA-A17-117021310076-3.

\section{СПИСОК ЛИТЕРАТУРЫ}

1. Вынос бериллия из коры выветривания гранитов. - URL: http://www.bitel.kg/osnovygeologii/942-vynosberilliya-iz-kory-vyvetrivaniya-granitov.html.

2. Дамбиев Э. Ц. Ландшафтная экология степей Бурятии / Э. Ц. Дамбиев, Б. Б. Намзалов, С. А. Холбоева. - Улан-Удэ : Издательство Бурятского государственного университета, 2006. - $185 \mathrm{c}$.

3. Дампилов Е-Ж. 3. География Кижинги / Е-Ж. З. Дампилов. - Кижинга, 2007. -87 с.

4. Дмитриева Т. И. Природно-хозяйственный комплекс Кижингино - Кодунской межгорной котловины и направления совершенствования природопользования на перспективу (Западное Забайкалье) : дис. ... канд. геогр. наук / Т. И. Дмитриева. - Улан-Удэ, 2007. - 197 с.

5. Куприянова И. И. Бериллиевые месторождения России / И. И. Куприянова, Е. П. Шпанов. - Москва : ГЕОС, 2011. - 353 c.

6. Куприянова И. И. Ермаковское флюорит - бериллиевое месторождение (Западное Забайкалье, Россия) / И. И. Куприянова, Е. П. Шпанов, В. И. Гальченко. Москва : ВИМС, 2009. - 73 с.

7. Лыхин Д. А. Рудоносный магматизм ЗападноЗабайкальской бериллиевой провинции: возраст, состав, источники (на примере Ермаковского, Оротского, Ауникского и Амандакского месторождений) : дис. ... канд. геол.-мин. наук / Д. А. Лыхин. - Москва, 2011. C. 235 .

8. Плюснин А. М. Количественная оценка преобразований в сульфидсодержащих отходах горнодобывающей промышленности / А. М. Плюснин, В. И. Гунин, Н. В. Беломестнова // Геохимия. - 2002. - № 11. С. 1197-1208.

9. Свойства элементов : справочник : в 2 кн. / под ред. М. Е. Дрица. - 3-е изд. - Москва : Руда и металлы, 2003. - Кн. 1. -448 c.

\section{REFERENCES}

1. Vynos berilliya iz kory vyvetrivaniya granitov [Removal of beryllium from the crust of weathering of granites]. Available at: http://www.bitel.kg/osnovygeologii/942vynos-berilliya-iz-kory-vyvetrivaniya-granitov.html. 
2. Dambiev E. Ts., Namzalov B. B., Kholboeva S. A., Landshaftnaya ekologiya stepey Buryatii [Landscape ecology of the steppes of Buryatia]. Ulan-Ude, Izdatel'stvo Buryatskogo gosudarstvennogo universiteta, 2006, $185 \mathrm{p}$.

3. Dampilov E-Zh. Z., Geografiya Kizhingi [Geography of Kizhinga]. Kizhinga, 2007, 87 p.

4. Dmitrieva T. I., Prirodno-khozyaystvennyy kompleks Kizhingino, Kodunskoy mezhgornoy kotloviny i napravleniya sovershenstvovaniya prirodopol'zovaniya na perspektivu (Zapadnoe Zabaykal'e) [The natural-economic complex of Kizhingino - Kodun intermountain basin and the direction of improving environmental management in the long term (Western Transbaikalia)]. Ulan-Ude, 2007, $197 \mathrm{p}$.

5. Kupriyanova I. I, Shpanov E. P, Berillievye mestorozhdeniya Rossii [Beryllium deposits of Russia]. Moscow, GEOS, 2011, 353 p.

6. Kupriyanova I. I., Shpanov E. P., Gal'chenko V. I., Ermakovskoe flyuorit, berillievoe mestorozhdenie (Zapad-

\section{Плюснин Алексей Максимович}

доктор геолого-минералогических наук, зам. директора Федерального государственного бюджетного учреждения науки Геологического института Сибирского отделения Российской академии наук, зав. лаб. гидрогеологии и геоэкологии, г. Улан-Удэ, E-mail: plyusnin@ginst.ru

Сандакова Дарима Митыповна

лаборант химического анализа ПАО «Бурятзолото», E-mail: Sandacova@mail.ru noe Zabaykal'e, Rossiya) [Ermakovskoye fluorite - beryllium deposit (Western Transbaikalia, Russia)]. Moscow: VIMS, 2009, 73 p.

7. Lykhin D. A., Rudonosnyy magmatizm ZapadnoZabaykal'skoy berillievoy provintsii: vozrast, sostav, istochniki (na primere Ermakovskogo, Orotskogo, Aunikskogo $i$ Amandakskogo mestorozhdeniy) [Ore magmatism of the West Transbaikal beryllium province: age, composition, sources (on the example of the Ermakovsky, Orotsky, Auniksky and Amandaksky deposits)]. Moscow, 2011, 235 p.

8. Plyusnin A. M., Gunin V. I., Belomestnova N. V., Kolichestvennaya otsenka preobrazovaniy $\mathrm{V}$ sul'fidsoderzhashchikh otkhodakh gornodobyvayushchey promyshlennosti [Quantification of transformations in sulfide-containing mining wastes]. Geokhimiya, 2002, No. 11, pp. 1197-1208.

9. Dritsa M. E., Svoystva elementov : spravochnik [Properties of elements: reference]. Moscow, Ruda i metally, 2003, Vol. 1, 448 p.

Plyusnin Alexey Maksimovich

Doctor of Geological and Mineralogical Sciences, Deputy Director of Geological Institute of Siberian Branch of the RAS, Head of Hydrogeology and Geoecology Laboratory, Ulan-Ude, E-mail: plyusnin@ginst.ru

Sandakova Darima Mitypovna

Laboratory assistant of chemical analysis of JSC «BuryatZoloto»,E-mail: Sandacova@mail.ru 